\title{
Development of Colorimetric Method for the Quantitative Analysis of Amlodipine Besylate in Dosage Form Using 4- Dimethyleaminobenzaldehyde as Derivatizing Reagent
}

\author{
Abdul Ghani Memon ${ }^{1}$, Ayaz Ali Memon ${ }^{2 *}$, Faqeer Mahboob Ali Rind ${ }^{1}$ \\ Zahid Ali Zounr ${ }^{1}$, Azhar Ali Ayaz Pirzada ${ }^{3}$, Nazir Ahmed Brohi ${ }^{4}$, \\ Mazhar Iqbal Khaskheli ${ }^{1}$ and Jamil Rahman Memon ${ }^{1}$ \\ ${ }^{1}$ Dr. M. A. Kazi Institute of Chemistry, University of Sindh, Jamshoro-76080, Pakistan. \\ ${ }^{2}$ National Centre of Excellence in Analytical Chemistry, University of Sindh, Jamshoro-76080, Pakistan. \\ ${ }^{3}$ Department of Electronic Engineering, University of Sindh, Jamshoro-76080, Pakistan. \\ ${ }^{4}$ Department of Microbiology, University of Sindh, Jamshoro-76080, Pakistan. \\ *Corresponding Author Email: ayazmemon33@gmail.com \\ Received 14 November 2019, Revised 02 May 2020, Accepted 20 June 2020
}

\begin{abstract}
The study is based on the determination of amlodipine besylate (AB) after derivatization with 4dimethylaminobenzaldehyde (DMAB) using UV/Visible spectrophotometer at $\mathrm{pH} 5$ to yield derivative that is measured at $\lambda \max 399 \mathrm{~nm}$. The calibration graph obtained was liner and fulfilled Beer Lambert's law in the concentration range $05-25 \mu \mathrm{g} / \mathrm{mL}$ of $(\mathrm{AB})$ and DMAB having coefficient of determination $\mathrm{R}^{2} 0.9988$ with RSD $0.93 \%$ and molar absorptivity $4.04 \times 10^{3}$ mole $^{-1}$ $\mathrm{cm}^{-1}$. Quantitative / analytical parameters such as $\mathrm{pH}$, heating time, temperature were optimized. Reagent concentration /volume, interday and intraday studies were also carried out. There was no effect of various solvents and additives observed on the determination of $\mathrm{AB}$ in commercially available drugs. The method is stable, accurate, rapid and simple for the study of imine derivative of $\mathrm{AB}$.
\end{abstract}

Keywords: Colorimetric method, Amlodipine besylate, 4-dimethyleaminobenzaldehyde, Derivatization

\section{Introduction}

A calcium channel blocker amlodipine besylate (AB) a family of dihydropyridine drug is highly specific for smooth arterial vascular muscle of heart. It is official drug for the cure of hypertension, abnormal and stable angina. Chemical name (4R, S)-3-ethyl 5-methyl 2(2amino-ethoxy-methyl)-4-(2-chlorophenyl)-1, 4dihydro6-methylpyridine-3, 5-dicarboxylate mono benzene sulphonate and is official in Extra Pharmacopoeia of Martindale (EPM) [1]. The impact of that medicine is controlled with marginal and coronary vasodilator properties. Estimation procedure mentioned for $\mathrm{AB}$ in
European Pharmacopoeia (EP) defines the RP (Reverse Phase) HPLC (High Performance Liquid Chromatography) processes [2] for the study of drug in bulk and dosage formulation. The former methods of analysis is based on HPLC [3-8], RP HPLC [2, 9-11], HPTLC (High Performance Thin Layer Chromatography) [12-15], GC (Gass Chromatography) [16], GCMS (Gass Chromatography Mass Spectrometry) [17], LCTMS (Liquid Chromatography Tandem Mass Spectroscopy) [18] and fluorimetry [19] referred in the previous work. Spectrophotometry is an investigative toll which is commonly used in drug 
determination due to its easy handling and economic benefits as a first add analysis. Spectrophotometry still goes to most commonly used analytical technique for qualitative and quantitative analysis of pharmaceutical formulations. It offers significant economic and experimental benefits over other technique. Two derivative spectrophotometric procedures were developed by Prasad and co-workers [20, 21] in mutual tablet preparation. The active content of drug in dosage form was studied by two different spectrophotometric procedures [22]. The primary procedure of determination is depend upon preparation of a complex of an ion pair with active content of medicine by the help of bromothymol sulfone phthalein, the complex was separated in chloroform and measured at $\lambda_{\max }$ of $405 \mathrm{~nm}$. The second procedure comprises the development of an oxidative coupling complex of medicine and hydrazone 3-methyl-2-benzothiazolinone $\mathrm{HCl}$ in ammonium ceric sulphate. The amlodipine charge transfer reaction with $\pi$ accepter such as $2,5 \mathrm{p}$ chloranilic acid and the other was tetrachloro-1,4 benzoquinone (chloranil) [23, 24] was utilized to analyse in pure and dosage form. Jain and Agarwal [25] have developed spectrophotometric procedures for concurrent investigation of lisinopril and amlodipine in dosage form based on diverse mode of assurance over extend 300-190 nm utilizing four diverse examining focuses at 213, 242, 271 and $300 \mathrm{~nm}$. Recently Becker et. al., [26] have been proposed a procedure which is based on NIR attached with integrating sphere with combination of interval partial least squares calibration (iPLS) and synergical siPLS procedure for mutual analysis of three drugs valsartan, hydrochlorothiazide and amlodipine. Hassan et. al., [27] develop HPLC and CE (Capillary Electrophoresis) procedure for concurrent determination of atorvastatin and amlodipine in the existence of their acidic degradation products in dosage form. Therefore, there's a necessity of a straight forward spectrophotometric procedure for the measure of AB. Current paper depicts modest, fast straight forward and touchy colorimetric process to measure of $\mathrm{AB}$. The process depending upon schiffs base reaction of primary amino group of amlodipine with aldehyde group of 4dimethyleaminoben-zaldehyde.
The general reaction is shown in scheme 1.

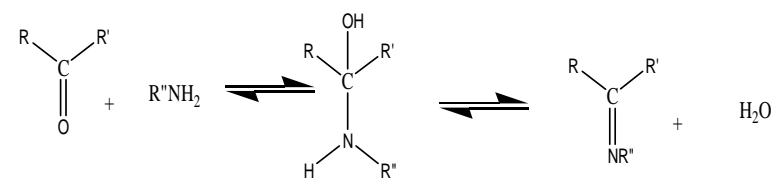

Scheme 1. A representative diagram for general reaction procedure of schiffs base reaction

\section{Materials and Methods \\ Analytical reagents and chemicals}

All the utilized reagents and chemicals were of analytical standard. The acetic acid, ethanol, hydrochloric acid, methanol, potassium chloride, sodium carbonate and sodium bicarbonate were purchased from Merck (Fair Lawn, NJ, USA). Pure AB was voluntarily donated by Bosch pharmaceuticals (PVT) LTD (Karachi, Pakistan), dimethyleaminobenzaldehyde (DMAB) and sodium acetate were purchased from EMD Chemicals (Gibbstown, NJ, USA).

\section{Preparation of stock solutions Buffer solution}

The buffer solutions of $\mathrm{pH}$ 1-10 were prepared by utilizing $\mathrm{pH}$ 1-10 buffer solutions by using (0.1M) hydrochloric acid, (0.1M) kallium chloride, (0.1M) acetic acid, (0.1M) natrium acetate, natrium carbonate (saturated solution), (0.1M) natrium bicarbonate, $(0.1 \mathrm{M})$ ammonium chloride and (0.1M) ammonia solution.

\section{Standard solution}

The $(1 \% \mathrm{w} / \mathrm{v})$ stock solution of $\mathrm{AB}$ was prepared by dissolving $0.1 \mathrm{~g}$ in $10 \mathrm{~mL}$ of methanol. Then diluted it up to $0.01 \%$ by taking $0.1 \mathrm{~mL}$ of standard solution into $10 \mathrm{~mL}$ celebrated volumetric flask and the volume was adjusted with methanol. The solution of DMAB 3\% was ready by dissolving $0.3 \mathrm{~g}$ dimethyleaminobenzaldehyde (DMAB) in $10 \mathrm{~mL}$ methanol.

\section{Instrumentation}

Perkin Elmer lambda 35 UV/Visible spectrometer (USA) and Thermo Orion 420A pH meter with glass electrode were used. 


\section{Procedure (A): analysis of amlodipine besylate standard}

The methanolic solution (1-5 $\mathrm{mL})$ containing $\mathrm{AB}(10-50 \mu \mathrm{g})$ was transferred to the $10 \mathrm{~mL}$ calibrated flask and then $2 \mathrm{~mL}$ DMAB $3 \%$ in methanol (w/v) was added followed by $1 \mathrm{~mL}$ acetate buffer $\mathrm{pH} 5$. The contents of the flak were warmed at $95^{\circ} \mathrm{C} \pm 1^{\circ} \mathrm{C}$ over water bath for $15 \mathrm{~min}$. The temperature of contents of flask were maintained at room temperature and filled with methanol up to the mark. The $\lambda_{\max }$ was observed at $399 \mathrm{~nm}$ compared with blank which was ready by same method without the addition of drug.

\section{Process (B): analysis of amlodipine besylate in dosage form}

Twenty tables were weighed precisely and pulverized. The amount of $25 \mathrm{mg}$ of $\mathrm{AB}$ was stirred and shaken in $10 \mathrm{~mL}$ methanol and the solution was kept for 10 to $15 \mathrm{~min}$. The content was filtered with Whatman filter paper no. 42 and washed with methanol and the volume was adjusted up to mark in $25 \mathrm{~mL}$ volumetric flask and finally the procedure for analysis of $\mathrm{AB}$ was applied as mentioned above.

\section{Results and Discussion}

Scheme 2 shows the reaction mechanism of derivatizing reagent (DMAB) with primary amino group of $A B$ drug during reaction method and new imine derivative AB-DMAB was prepared.

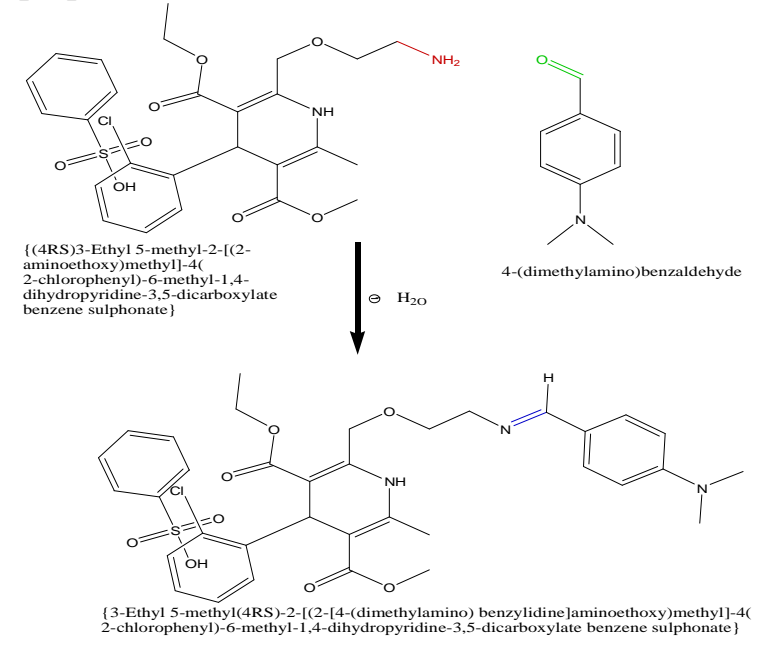

Scheme 2. Synthetic route for the derivatization of $\mathrm{AB}$ with DMAB as derivatizing reagent
$A B$ reacts with $D M A B$ to form an imine derivative $A B-D M A B$ which gives absorbance maximally $\left(\lambda_{\max }\right)$ at $399 \mathrm{~nm}$ with molar absorptivity of $4.04 \times 10^{3} \mathrm{~mole}^{-1} \mathrm{~cm}^{-1}$. The DMAB was confirmed as a derivatizing reagent for the colorimetric analysis of AB. The particular parameters were optimized which impact on the preparation of $\mathrm{AB}-\mathrm{DMAB}$ derivative likewise effect of $\mathrm{pH}$, effect of reagent concentration $\mathrm{DMAB}$, temperature and time of heating.

\section{Analytical parameters optimization}

Selection of wavelength by using absorption spectra

Wavelength of maximum absorbance play vital role for quantitative analysis. It is very crucial to choose the wavelength where derivative gives optimal absorbance. The absorbance of 10 $\mu \mathrm{g} / \mathrm{mL}$ of $\mathrm{AB}$ and $\mathrm{DMAB}$ derivative was measured within the range of $350-450 \mathrm{~nm}$ after heating at $95^{\circ} \mathrm{C} \pm 1^{\circ} \mathrm{C}$ for 15 min using buffer $\mathrm{pH}$ 4. It is clear that the $\lambda$ max was in visible range and at $399 \mathrm{~nm}$ against reference and was selected as optimal.

Selection of optimal temperature and heating time for the preparation of derivative

To reach the prime value of absorbance for an analyte the optimization of optimum heating time was measured at $399 \mathrm{~nm}$ for 0-30 min with an intermission of $5 \mathrm{~min}$. A prime absorbance value was seen after heating for $15 \mathrm{~min}$ at $95{ }^{\circ} \mathrm{C} \pm 1{ }^{\circ} \mathrm{C}$ and was considered as optimum (Fig.1).

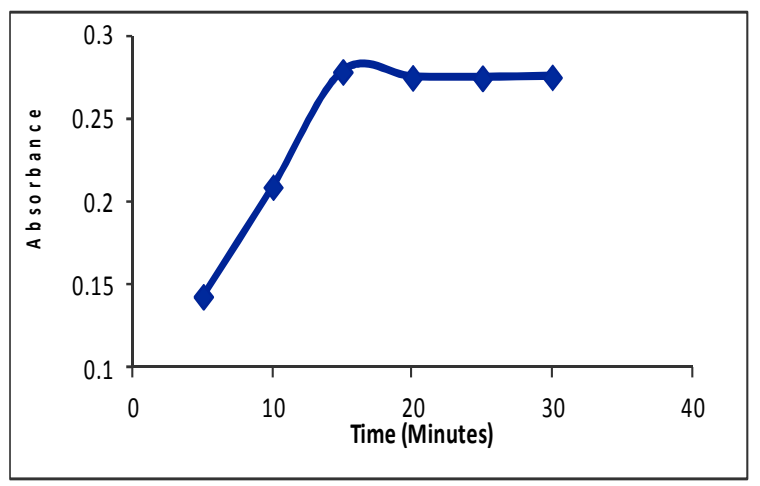

Figure 1. Effect of heating time on absorbance of derivative 
Optimization volume and concentration of reagent

The influence of adding different volumes (0.5-3.5 mL) of DMAB (3\% in methanol) with intermission of $0.5 \mathrm{~mL}$ on absorbance of $10 \mu \mathrm{g} / \mathrm{mL}$ of $A B$ was examined. No change in increase of absorbance was observed after addition $2 \mathrm{~mL}$ of $3 \%$ reagent. Therefore, the addition of $2 \mathrm{~mL} \mathrm{3 \%}$ DMAB solution was considered as optimal (Fig. $2 a$ and $2 b$ ).
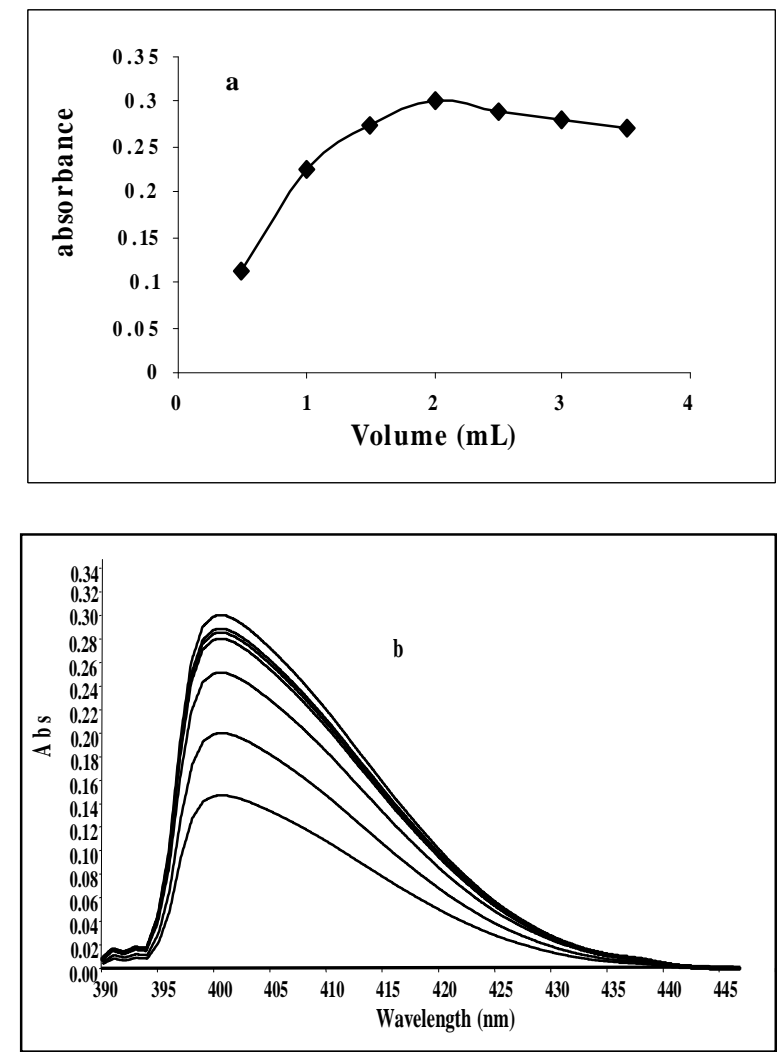

Figure 2. Effect of volume of reagent on absorbance of derivative, (a) graphical representation between absorbance and volume and (b) UV-spectra of all readings at $\lambda_{\max }$ of $399 \mathrm{~nm}$.

\section{pH effect on derivative}

At the optimum conditions, the effect of addition of $1 \mathrm{~mL}$ of $0.1 \mathrm{M}$ buffer solution at $\mathrm{pH}$ range 1-10 was studied. A regular increase in absorbance was watched from buffer $\mathrm{pH} 1-5$ and the most extreme absorbance was obtained at $\mathrm{pH} 5$ (Fig. 3a). The addition of buffer $\mathrm{pH} \mathrm{8-10} \mathrm{gives}$ precipitation. The buffer $\mathrm{pH} 5$ was taken as optimal. The UV-spectra was obtained at lambda max $397 \mathrm{~nm}$ (Fig. 3b).
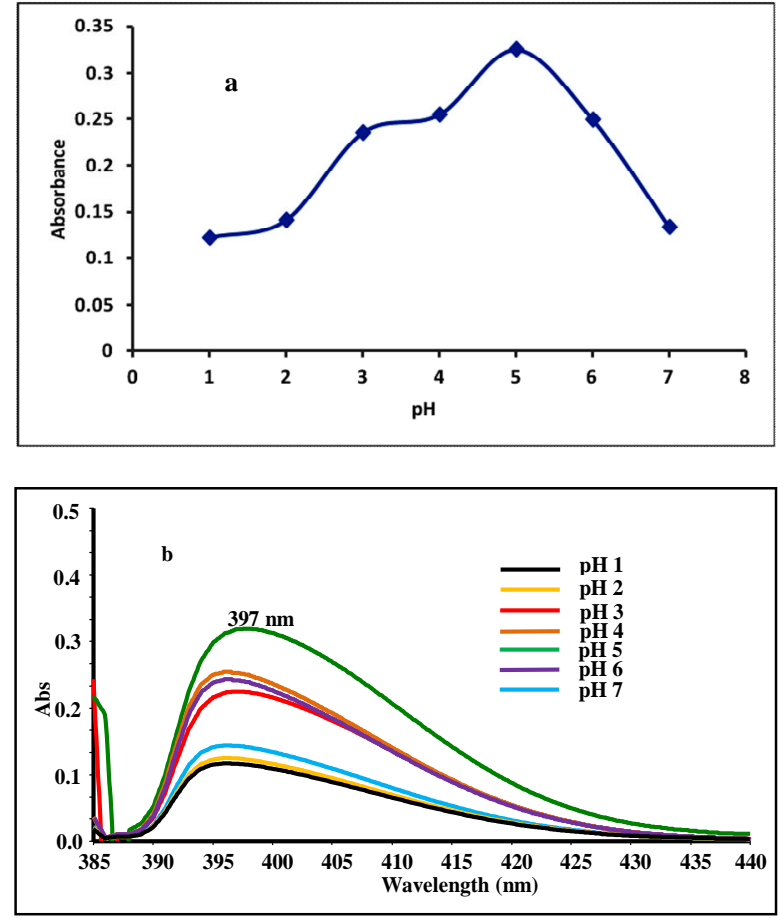

Figure 3a-b. Effect of $\mathrm{pH}$ on absorbance of derivative

\section{Effect of solvent}

The addition of various solvents such as propanol, isopropanol, butanol, n-hexane, acetonitrile, ethyleacetate, tetrahydrofuran, water and acetone has no effect on absorbance. The study of solvent effects was checked by addition 1 $\mathrm{mL}$ and $2 \mathrm{~mL}$ of mentioned solvents and $2 \mathrm{~mL}$ of $3 \%$ methanolic solution of DMAB and $1 \mathrm{~mL}$ acetate buffer $\mathrm{pH} 5$ then heated for $15 \mathrm{~min}$ at $95^{\circ} \mathrm{C} \pm 1^{\circ} \mathrm{C}$ as shown in Table 1 .

Table1. Effect of different solvents on absorbance of derivative.

\begin{tabular}{lccc}
\hline \multicolumn{1}{c}{ Solvents } & $\begin{array}{c}\text { Volume } \\
(\mathbf{m L}) \\
\text { Added }\end{array}$ & $\begin{array}{c}\text { Absorbance } \\
\text { with } \\
\text { methanol }\end{array}$ & $\begin{array}{c}\text { Absorbance } \\
\text { with } \\
\text { other solvents }\end{array}$ \\
\hline 1-propanol & 2 & 0.3021 & 0.3020 \\
Iso-propanol & 2 & 0.3021 & 0.3019 \\
Butanol & 2 & 0.3021 & 0.3017 \\
n-hexane & 2 & 0.3021 & 0.3020 \\
Acetonitrile & 2 & 0.3021 & 0.3018 \\
Ethyl acetate & 2 & 0.3021 & 0.3017 \\
Tetrahydrofuran & 2 & 0.3021 & 0.3021 \\
Water & 2 & 0.3021 & 0.1603 \\
Acetone & 2 & 0.3021 & 0.3016 \\
\hline
\end{tabular}


Table 2. Effect different possible additives on the absorbance of derivative

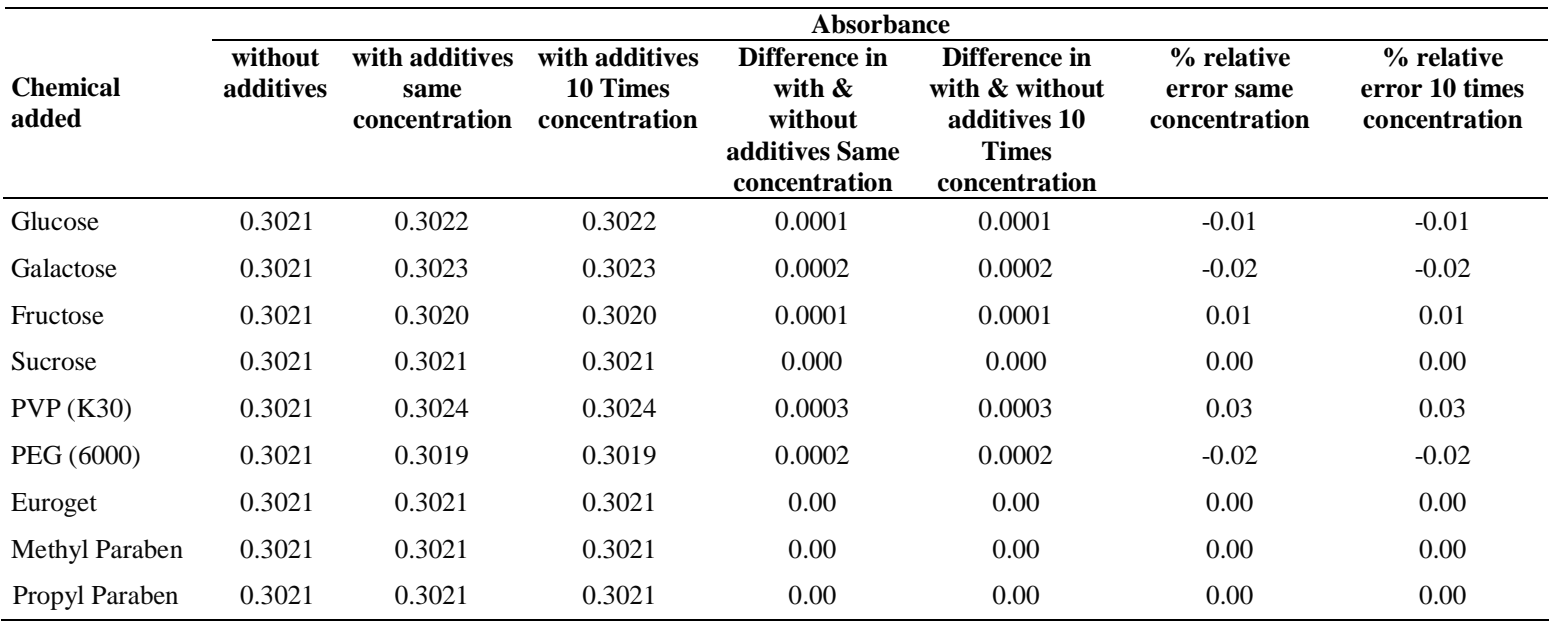

\section{Effect of mixing order of reagents}

The mixing sequence of reagent for the derivatization procedure plays an imperative part in improvement of absorbance and precision of result. Different orders of mixing were applied in the current work. It was noticed that the addition of $1 \mathrm{~mL}$ buffer $\mathrm{pH} 5$ in the $25 \mu \mathrm{g} / \mathrm{mL}$ of $\mathrm{AB}$ followed by addition of $2 \mathrm{~mL} \mathrm{3 \%} \mathrm{DMAB} \mathrm{results}$ in decreasing in the absorbance value. Changing the sequence of mixing by taking $\mathrm{DMAB}$ first then add buffer followed by $\mathrm{AB}$ solution also has shown low rate of absorbance. The maximum absorbance resulted when $2 \mathrm{~mL}$ of reagent $D M A B$ was mixed to the pure $A B$ solution followed by addition of $1 \mathrm{~mL}$ buffer solution $\mathrm{pH} 5$.

\section{Excipient study}

The influence of related additives likewise, glucose, PVP (polyvinylpyrrolidone) k30, galactose, euroget fructose, sucrose, polyethylene glycol (PEG-6000) and M-paraben $\mathrm{P}$-paraben was investigated in same and ten times the amount of $\mathrm{AB}$. It was seen that no one of the additive affected with any variation in absorbance of more than $\pm 5 \%$ error (Table 2).

\section{Percent recovery from dosage form}

Table 3 shows the percent recovery of $A B-D M A B$ derivative from five different pharmaceutical formulations by following mentioned procedure (B). The percent recovery was found more than $98 \%$ in all selected formulations.

Table 3. Analysis of $\mathrm{AB}$ from pharmaceutical preparations

\begin{tabular}{cccc}
\hline $\begin{array}{c}\text { Drug } \\
\text { brands }\end{array}$ & $\begin{array}{c}\text { Amount labeled } \\
\text { per tablet }(\mathbf{m g})\end{array}$ & $\begin{array}{c}\text { Amount found } \\
\text { per tablet }(\mathbf{m g})\end{array}$ & $\begin{array}{c}\text { Recovery } \\
(\%)\end{array}$ \\
\hline Cordium & 10 & 9.87 & 98.7 \\
Lodopin & 10 & 9.95 & 99.5 \\
M-low & 10 & 10.02 & 100.2 \\
Norvasc & 10 & 9.97 & 99.7 \\
Sofvasc & 10 & 10.004 & 100.04 \\
\hline
\end{tabular}

\section{Stability of derivative}

The stability of AB-DMAB derivative was verified in the terms of absorbance at the concentration of $10 \mu \mathrm{g} / \mathrm{mL} \mathrm{AB}$ but no remarkable variation in the absorbance of more than $3 \%$ was detected within $48 \mathrm{~h}$.

\section{Calibration graph (Beer's Law)}

The impact of change in the concentration of $\mathrm{AB}$ on its absorbance was studied. A linear calibration curve was obtained which fulfilled the Beer's law within the concentration range 5-25 $\mu \mathrm{g} / \mathrm{mL}$ of $\mathrm{AB}$ with coefficient of determination $\mathrm{R}^{2}$ 0.9988 (Fig. 4). 


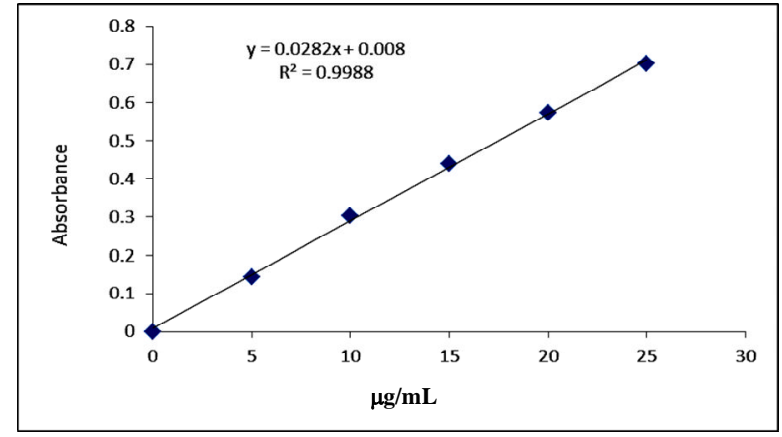

Figure 4. Calibration curve of derivative

\section{Day to day reproducibility/repeatability}

For the stability of derivative, the assessment of interday and intraday repeatability of the procedure is an important parameter. The methanolic solution of $\mathrm{AB} 10 \mu \mathrm{g} / \mathrm{mL}$ was taken in three separate $(10 \mathrm{~mL})$ calibrated flasks and the method was applied as mentioned procedure (A). The mentioned method was repeated for three days $(n=3)$. The average mean absorbance of intraday and interday reproducibility for imine derivative was seen as 0.3021 and 0.2790 with (RSD) values $0.93 \%$ and $1.16 \%$, respectively (Table 4).

Table 4. Sensitivity comparison of proposed method for imine derivative with $\mathrm{AB}$.

\begin{tabular}{cccc}
\hline Parameters & & $\begin{array}{c}\text { Imine } \\
\text { derivative }\end{array}$ & $\begin{array}{c}\text { Amlodipine } \\
\text { drug }\end{array}$ \\
\hline $\begin{array}{c}\text { Precision } \\
(\mathrm{n}=3)\end{array}$ & $\begin{array}{c}\text { Inter-day } \\
\text { Intra-day }\end{array}$ & $\begin{array}{l}0.2790 \\
0.3021\end{array}$ & -- \\
$\begin{array}{c}\text { Sensitivity } \\
\left(\mu \mathrm{gmL}^{-1}\right)\end{array}$ & $\begin{array}{c}\text { Limit of detection } \\
\text { (LOD) }\end{array}$ & 0.992 & 1.67 \\
& $\begin{array}{c}\text { Limit of } \\
\text { quantification } \\
\text { (LOQ) }\end{array}$ & 3.31 & 3.67 \\
\hline
\end{tabular}

\section{Conclusion}

The new developed method is modest, easy, linear, straight forward, repeatable and fast using low cost common laboratory chemical reagents. The developed procedure validated for the quantitative determination of amlodipine besylate drug. The amlodipine besylate drug was derivatized by 4-dimethyleaminobenzaldehyde reagent with buffer $(\mathrm{pH} 5)$ on heating at $95^{\circ} \mathrm{C}$ for $15 \mathrm{~min}$. The content of derivative absorbs in visible region at $\lambda_{\max }$ of $399 \mathrm{~nm}$ with bathochromic shift. The developed procedure avoids any interference with binding material which might absorb in UV region. The process was used for the assay of amlodipine besylate on commercially available products.

\section{References}

1. Martindale The Extra Pharmacopoeia, 31st edn., Royal Pharmaceutical Society, London, (1996) 819.

http://dx.doi.org/10.4236/fns.2016.712110.

2. European Pharmacopoeia, 3rd edn, Council of Europe - Strasbourg, (2001) Supplement, 431.

3. C. Mustafa, K. M. Sinan and A. S. S. Selma, Braz. J. Pharm. Sci., 46 (2010) 761.

https://doi.org/10.1590/S198482502010000400018.

4. K. Shimooka, Y. Sawada and H. Tatematsu, J. Pharm. Biomed. Anal., 7 (1989) 1267. https://doi.org/10.1016/07317085(89)80130-X.

5. P. K. F. Yeung, S. J. Mosher and P. T. Pollack, J. Pharm. Biomed. Anal., 9 (1991) 565.

https://doi.org/10.1016/07317085(91)80178-C.

6. R. V. Patki, C. P. Tamhanker and H. P. Tipnis, Ind. Drugs, 31 (1994) 560. https://doi.org/10.1016/S07317085(99)00210-1.

7. M. Josefsson, A.-L. Zackrisson and B. Norlander, J. Chromatogr. B: Biomed. Appl., 672 (1995) 310. https://doi.org/10.1016/0378-4347 (95)00231-7.

8. F. Shang and K. Shang, Zhonggno Yiyao Gongye Zazhi, 27 (1996) 411.

9. A. B. Avadhanulu, J. S. Srinivas and Y. Anjaneyulu, Ind. Drugs, 33 (1996) 36.

10. S. R. Sankar, M. J. Nanjan, M. Vasudevan, N. Shaat and B. Suresh, Ind. J. Pharm. Sci., 59 (1997) 171.

11. V. J. Dhorda and N. B. Shetkar, Ind. Drugs, 36 (1999) 638.

12. P. S. Jain, M. K. Patel, S. B. Bari and S. J. Surana, Ind. J. Pharma. Sci., (2012) 152. https://DOI:10.4103/0250-474X.103849 
13. K. K. Pandya, M. Satia, T. P. Gandhi, I. A. Modi, R. I. Modi and B. K. Chakravarthy, J. Chromatogr. B: Biomed. Appl., 667 (1995) 315.

https://doi.org/10.1016/03784347(95)00016-C.

14. K. Ilango, P. B. Kumar and V. R. V. Prasad, Ind. J. Pharm. Sci., 59 (1997) 336.

15. A. P. Agrekar and S. G. Powar, J. Pharm. Biomed. Anal., 21 (2000) 1137. https://doi.org/10.1016/S07317085(99)00210-1.

16. A. P. Beresford, P. V. Macrae, D. A. Stopher and B. A. Wood, J. Chromatogr. B, 420 (1987) 178.

https://doi.org/10.1016/03784347(87)80170-6

17. Y. Feng, Q. Meng, X. Guo, D. Yang, and Y. He, Guan. Yaoxue. Xueb., 14 (1998) 111. https://doi.org/10.1016/03784347(87)80170-6.

18. T. Yasuda, M. Tanaka and K. Iba, J. Mass Spectrom., 31 (1996) 879. https://doi.org/10.1002/(SICI)10969888(199608)31:8\%3C879::AIDJMS373\%3E3.0.CO;2-F.

19. Y. E. Mohamed, M. E. K. Naglaa, A. M. Bahia and G. M. Nashwa, Bull. Fac. Pharm., 36 (1998) 1.

20. C. V. N. Prasad, C. Parihar, T. R. Chowdhary, S. Purohit and P. Parimoo, Pharm. Pharmacol. Commun., 4 (1998) 325. https://doi.org/10.1111/j.20427158.1998.tb00705.x.
21. C. V. N. Prasad, R. N. Saha and P. Parimoo, Pharm. Pharmacol. Commun., 5 (1999) 383. https://doi.org/10.1211/14608089912873502 $\underline{7}$.

22. K. Sridhar, C. S. P. Sastry, M. N. Reddy, D. G. Sankar and K. R. Srinivas, Anal. Lett., 30 (1997) 121. https://doi.org/10.1080/00032719708002295.

23. N. Rahman, and S. N. H. Azmi, Anal. Sci., 16 (2000) 1353.

https://doi.org/10.2116/analsci.16.1353.

24. G. Gromo, J. Mann and J. D. Fitzgerald, Cold Spring Harb. Perspect. Med., 4 (2014) 014092.

https://doi: $10.1101 /$ cshperspect.a014092

25. H. K. Jain and R. K. Agrawal, Ind. Drugs, 37 (2000) 196.

26. Natana Becker, Gabriela R. Foresti, Willian R. R. Almeida, Karine F. Nicorena, Marco F. Ferrão and E. B. Fabiana, J. Appl. Pharm. Sci., 7 (2017) 074. https://doi.org/ 10.7324/JAPS.2017.71111.

27. S. A. Hassan, E. S. E. Maissa, Y. Salem and B. A. El-Zean, Acta Pharm., 66 (2016) 479. https://doi.org/ 10.1515/acph-2016-0040. 